\title{
Properties and durability of HPC with tyre rubber wastes
}

\author{
F. Azevedo, F. Pacheco-Torgal *, C. Jesus, J.L. Barroso de Aguiar, A.F. Camões \\ C-TAC: Territory, Environment and Construction Research Centre, Sustainable Constrution Group, School of Engineering, University of Minho, Guimarães, Portugal
}

\section{A R T I C L E I N F O}

\section{Article history:}

Received 17 October 2011

Received in revised form 29 January 2012

Accepted 25 February 2012

\section{Keywords:}

Tyre rubber wastes

Concrete

Mechanical strength

Capillary water absorption

Sulphuric acid attack

\begin{abstract}
A B S T R A C T
An estimated 1000 million tyres reach the end of their useful lives every year and 5000 millions more are expected to be discarded in a regular basis by the year 2030. Up to now a small part is recycled and millions of tyres are just stockpiled, landfilled or buried. This paper presents results about the properties and the durability of HPC with partial replacement of sand by tyre rubber wastes. Fly ash and metakaolin are used as partial cement replacement. The durability performance was assessed by means of capillary water absorption and resistance to sulphuric acid attack. The results show the existence of a synergetic effect between fly ash and metakaolin that minimizes the strength loss associated to the use of rubber waste. Results also show that is possible to use rubber waste up to $15 \%$ and still maintain a high resistance to acid attack. The mixes with $45 \%$ fly ash and $15 \%$ metakaolin show a much higher resistance to sulphuric acid attack than the reference mix independently of the rubber waste content.
\end{abstract}

(c) 2012 Elsevier Ltd. All rights reserved.

\section{Introduction}

All over the world billions of tyres are being discarded and buried representing a serious ecological threat. By the year 2030 the number of tyres from motor vehicles is expected to reach 1200 million representing almost 5000 million tyres to be discarded in a regular basis [1]. The implementation of the Landfill Directive 1999/31/EC [2] and the End of Life Vehicle Directive 2000/53/EC [3] banned the landfill disposal of waste tyres creating the driving force behind the recycling of these wastes. A possible solution relates to the use of tyre rubber waste as aggregate replacement in concrete. Tyre rubber aggregates are obtained from waste tyres using two different technologies: mechanical grinding at ambient temperature or cryogenic grinding at a temperature below the glass transition temperature. The first method generates chipped rubber to replace coarse aggregates. As for the second method it usually produces crumb rubber to replace fine aggregates [1]. Some research has already been conducted on the used of waste tyre as aggregate replacement in concrete showing that rubber aggregates reduces concrete workability [4] and compressive strength [5]. The strength loss is much more profound when coarse rubber aggregates are used which is due to the low adhesion between these wastes and the cement paste, but several authors recommend different treatments to enhance the adhesion of the rubber aggregates [6-8]. Previous investigations also show that concrete composites containing tyre rubber waste are known for

\footnotetext{
* Corresponding author.

E-mail address: torgal@civil.uminho.pt (F. Pacheco-Torga).
}

their high toughness [9], meaning that they are specially recommended for concrete structures located in areas of severe earthquake risk and also for the production of railway sleepers. Although the studies about the properties of concrete with tyre rubber wastes are abundant the ones related to the durability are scarce justifying further investigations. Besides, so far investigations using rubber wastes were made using normal-strength concretes thus meaning that using a low water/binder concrete (HPC [10]) constitutes a research area yet to be explore.

\section{Experimental work}

\subsection{Materials, mix design and concrete mixing}

The characteristics of the aggregates used to make the concrete mixtures are shown in Table 1 and Fig. 1a. The rubber waste was supplied by Recipneu and was produced by cryogenic grinding at a temperature below the glass transition temperature. It has a dimension between $1 \mathrm{~mm}$ and $2.4 \mathrm{~mm}$ (Fig. 1b). An ordinary Portland cement (CEM II 42.5) was used. The chemical composition of the cement is presented in Table 2 . The metakaolin used in this study was subjected to a thermal treatment at $650^{\circ} \mathrm{C}$ during a few seconds using a flash calcination apparatus. It has a BET surface of $19.2982 \mathrm{~m}^{2} / \mathrm{g}$ and its chemical composition is shown in Table 3. The fly ash was supplied by Endesa Generation S.A. and according to the NP EN 450-1 it belongs to $\mathrm{B}$ class and has an $\mathrm{N}$ class fineness modulus. Its chemical composition is shown in Table 4. Several concrete mixes with a water/binder ratio of 0.35 and $500 \mathrm{~kg} / \mathrm{m}^{3}$ of binder were designed using the Faury concrete mix design method $(A=26, B=1.5)[11,12]$. The concrete mixes are described in Table 5 . The concrete mixtures were named according to their content. For instance C_5RW_15CV_15MK is related to a concrete mixture with $5 \%$ of rubber waste, $15 \%$ fly ash and $15 \%$ of metakaolin. A second generation super plasticizer based on polycarboxylic ether polymers (Glenium Sky 526) was used at appropriate percentages in order to retain the slump of the fresh concrete between 100 and $150 \mathrm{~mm}$ (class S3 of NP EN 206-1 [13]). An extra concrete mix was designed complying with the requirements of EN 
Table 1

Characteristics of the sand and of the coarse aggregates.

\begin{tabular}{lllllll}
\hline & Max dimension & Fineness modulus & Fine content & Density $\left(\mathrm{kg} / \mathrm{m}^{3}\right)$ & Water absorption & Resistance to abrasion in the Los Angeles test $(\%)$ \\
\hline Sand & 5.6 & 3.3 & $\leqslant 3$ & 2660 & 0.2 & - \\
Coarse aggregates & 8 & 5.9 & $\leqslant 1.5$ & 2620 & 0.6 & $\leqslant 40$ \\
\hline
\end{tabular}

(a)

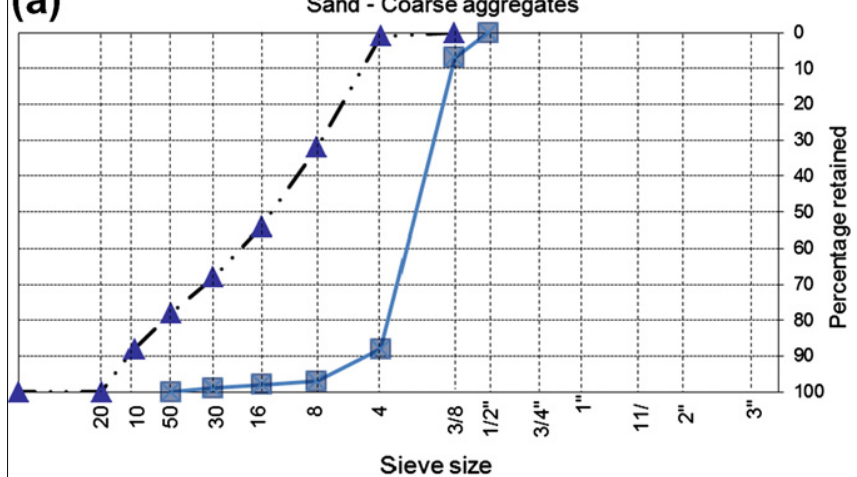

(b)

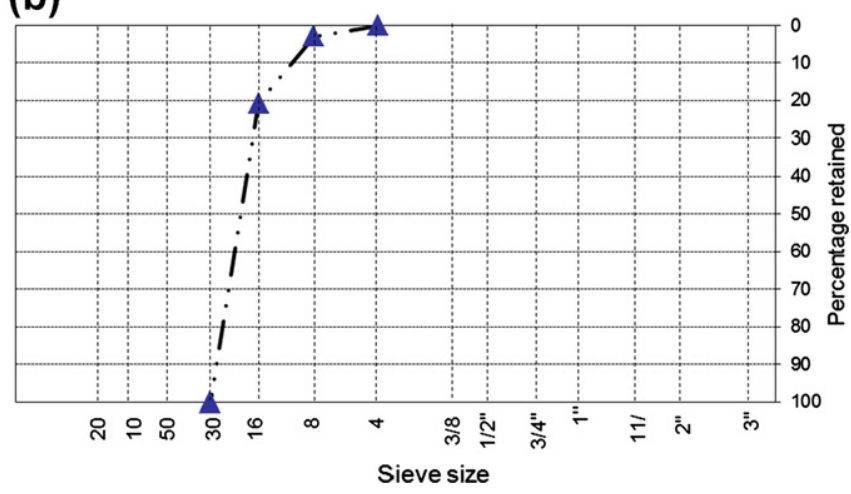

Fig. 1. Particle size distribution: (a) Sand and coarse aggregate; (b) rubber waste.

206-1. Concrete. Part 1: Specification, performance, production and conformity for concrete structures exposed to highly aggressive chemical environment (class XA3). This mixture had a 28 days compressive strength of $60 \mathrm{MPa}$.

\subsection{Experimental procedures}

2.2.1. Compressive strength

The compressive strength was performed under NP EN 206-1 [13]. The concrete specimens were conditioned at a temperature equal to $21 \pm 2{ }^{\circ} \mathrm{C}$ cured in a moist chamber until they have reached the testing ages. Tests were performed on $50 \times 50 \times 50 \mathrm{~mm}^{3}$ concrete specimens. Compressive strength for each mixture was obtained from an average of three cubic specimens determined at the age of 7 and 28 days of curing.
Table 2

Portland cement composition.

\begin{tabular}{ll}
\hline Constituents (\%) & Cement II-42.5 \\
\hline $\mathrm{SiO} 2$ & 10.26 \\
$\mathrm{Al}_{2} \mathrm{O}_{3}$ & 1.657 \\
$\mathrm{Fe}_{2} \mathrm{O}_{3}$ & 3.996 \\
$\mathrm{CaO}$ & 76.928 \\
$\mathrm{MgO}$ & 0.884 \\
$\mathrm{Na}_{2} \mathrm{O}$ & 0.000 \\
$\mathrm{~K}_{2} \mathrm{O}$ & 1.048 \\
$\mathrm{SO}_{3}$ & 4.243 \\
$\mathrm{TiO}_{2}$ & 0.326 \\
$\mathrm{P}_{2} \mathrm{O}_{5}$ & 0.105 \\
$\mathrm{Zn}^{\mathrm{ZrO}}$ & 0.242 \\
Other minor oxides & 0.062 \\
\end{tabular}

2.2.2. Capillary water absorption

Capillary water absorption was carried out using cubic specimens with $15 \mathrm{~cm}$ high. After 28 days in a moist chamber the specimens were placed in an oven at $45^{\circ} \mathrm{C}$ for 14 days. The test consists in placing the specimens in a container with enough water to maintain immersed one of the sides of the sample. This test was carried out according to the Standard LNEC E393 [14]. Water absorption has been measured after $(10,30,60,90,120,180,360,480,1440,2880$ and 4320) min. Capillarity water absorption was obtained from an average of three specimens.

\subsubsection{Resistance to sulphuric acid attack}

The resistance to acid attack followed a variation of the ASTM C-267 (Standard test methods for chemical resistance of mortars, grouts, and monolithic surfacings and polymer concretes).

The test used in the present investigation consists in the immersion of $150 \times 150 \times 150 \mathrm{~mm}^{3}$ concrete specimens with 56 days curing in a $10 \%$ of sulphuric solution during 28 days. The resistance to acid attack was assessed by the differences in weight of dry specimens before and after acid attack at 1, 3, 7, 14 and 28 days.

\section{Results and discussion}

\subsection{Compressive strength}

Fig. 2 shows the compressive strength of the mixes with rubber wastes. The standard deviation was low and the coefficient of variation do not exceed $10 \%$ meaning that the results were statistical relevant. The increase of rubber wastes leads to serious compressive strength loss as reported by other authors [5]. At this level only the $5 \%$ rubber wastes mix seems to be feasible. When compared to the compressive strength of the reference mix, this mix

Table 3

Chemical composition of metakaolin (\%).

\begin{tabular}{lllllllll}
\hline LOI & $\mathrm{SiO}_{2}$ & $\mathrm{Al}_{2} \mathrm{O}_{3}$ & $\mathrm{Fe}_{2} \mathrm{O}_{3}$ & $\mathrm{~K}_{2} \mathrm{O}$ & $\mathrm{Na}_{2} \mathrm{O}$ & $\mathrm{MgO}$ & Other minor oxides \\
\hline 1.56 & 54.25 & 39.90 & 1.51 & 1.79 & 0.08 & 0.18 & 0.41 \\
\hline
\end{tabular}

Table 4

Chemical composition of the fly ash (\%).

\begin{tabular}{llllll}
\hline $\mathrm{SiO}_{2}+\mathrm{Al}_{2} \mathrm{O}_{3}+\mathrm{Fe}_{2} \mathrm{O}_{3}$ & Reactive $\mathrm{SiO}_{2}$ & Free CaO & Reactive CaO & $\mathrm{K}_{2} \mathrm{O}+\mathrm{Na}_{2} \mathrm{O}$ & $\mathrm{MgO}_{3}$ \\
\hline 89.9 & 40.8 & 0.1 & 2.7 & 0.25 & 1.9 \\
\hline
\end{tabular}


Table 5

Concrete mix proportions per cubic metre of concrete.

\begin{tabular}{|c|c|c|c|c|c|c|c|c|}
\hline & Cement (kg) & Fly ash (kg) & Metakaolin (kg) & Sand (kg) & Rubber waste (kg) & Coarse aggregates $(\mathrm{kg})$ & Water (l) & SP (1) \\
\hline C_ref & 500 & - & - & 1256 & - & 430 & 174 & 8.7 \\
\hline C_15MK & 425 & - & 75 & 1231 & - & 440 & 174 & 8.7 \\
\hline C_30CV & 350 & 150 & - & 1179 & - & 461 & 174 & 8.7 \\
\hline C_60CV & 200 & 300 & - & 1106 & - & 488 & 174 & 8.7 \\
\hline C_5RW & 500 & - & - & 1192 & 63 & 430 & 174 & 8.7 \\
\hline C_10RW & 500 & - & - & 1130 & 126 & 430 & 174 & 8.7 \\
\hline C_15RW & 500 & - & - & 1067 & 188 & 430 & 174 & 8.7 \\
\hline C_5RW_30CV & 350 & 150 & - & 1120 & 60 & 461 & 174 & 8.7 \\
\hline C_5RW_60CV & 200 & 300 & - & 1151 & 55 & 488 & 174 & 8.7 \\
\hline C_10RW_30CV & 350 & 150 & - & 1061 & 118 & 461 & 174 & 8.7 \\
\hline C_10RW_60CV & 200 & 300 & - & 995 & 111 & 488 & 174 & 8.7 \\
\hline C_15RW_30CV & 350 & 150 & - & 1002 & 177 & 461 & 174 & 8.7 \\
\hline C_15RW_60CV & 200 & 300 & - & 940 & 166 & 488 & 174 & 8.7 \\
\hline C_5RW_15CV_15MK & 350 & 75 & 75 & 1132 & 60 & 455 & 174 & 8.7 \\
\hline C_5RW_45CV_15MK & 200 & 225 & 75 & 1063 & 56 & 483 & 174 & 8.7 \\
\hline C_10RW_15CV_15MK & 350 & 75 & 75 & 1073 & 119 & 455 & 174 & 8.7 \\
\hline C_10RW_45CV_15MK & 200 & 225 & 75 & 1007 & 179 & 483 & 174 & 8.7 \\
\hline C_15RW_15CV_15MK & 350 & 75 & 75 & 1014 & 179 & 455 & 174 & 8.7 \\
\hline C_15RW_45CV_15MK & 200 & 225 & 75 & 951 & 168 & 483 & 174 & 8.7 \\
\hline C_XA3 & 360 & - & - & 1438 & - & 493 & 128 & 6 \\
\hline
\end{tabular}

Ref - control; MK - metakaolin; CV - fly ash; RW -tyre rubber waste; SP - super plasticizer.

has a $31 \%$ compressive strength decrease at 28 days curing. The mixes with a higher rubber percentage show a very severe compressive strength loss. Fig. 3a shows the compressive strength of mixes with partial replacement of cement by fly ash and metakaolin. The results confirm previous investigations [15], showing that fly ash has very slow hydration characteristics thus providing very little contribution to early age strength, as to metakaolin possess a high reactivity with calcium hydroxide having the ability to accelerate cement hydration [16]. Fig. 3b shows the compressive strength of mixes with rubber wastes and partial replacement of cement by fly ash. The mix with $5 \%$ rubber wastes and 30\% fly ash is the only one that is associated to a high compressive strength, above $40 \mathrm{MPa}$, exceeding the majority of compressive strength classes used in the construction industry [17]. Fig. 3c shows the compressive strength of mixes with rubber wastes and partial replacement of cement by fly ash and metakaolin. The results show the synergetic effect of fly ash and metakaolin minimizes the strength loss associated to the use of rubber waste. When compared to the compressive strength of the reference mix, the one with $5 \%$ rubber wastes and $15 \%$ fly and $15 \%$ metakaolin has a $23 \%$ compressive strength decrease at 28 days curing.

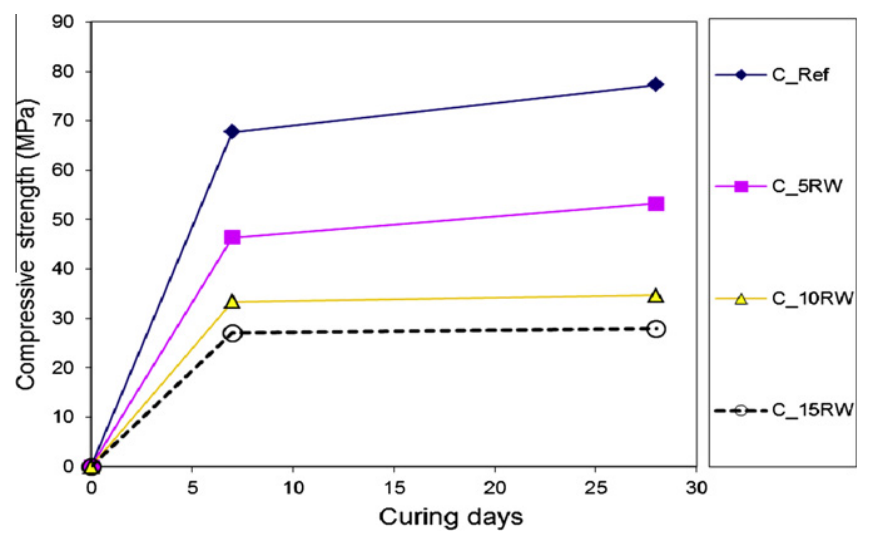

Fig. 2. Compressive strength of the mixes with rubber wastes.

\subsection{Capillary water absorption}

Fig. 4 shows the capillary water absorption coefficients of mixes with rubber wastes. As expected an increase in the rubber percentage leads to high water absorption coefficients. The partial replacement of cement by pozzolanic additions also leads to an increase in the water absorption coefficients (Fig. 5a). Nevertheless, the capillary water absorption of all the concrete mixes used in this investigation is very low (Fig. 5b and c). As a comparison a C20/25 strength class concrete (the most used strength class in Europe [17] has capillary water absorption coefficient between 0.85 and $2.6 \mathrm{~kg} / \mathrm{m}^{2} \mathrm{~h}^{0.5}[18]$. Some authors even report the use of surface treatments to achieve concrete surfaces with similar capillary water absorption coefficients [19].

\subsection{Resistance to sulphuric acid attack}

Fig. 6 shows the mass loss after sulphuric acid attack of mixes with rubber wastes. The increase in the rubber percentage leads to a higher mass loss degree. The mix with $15 \%$ metakaolin and the mix with $30 \%$ fly ash underperformed against the reference mix, however, that was not the case of the mix with $60 \%$ fly ash which shows a mass loss after 28 days that is $10 \%$ lesser when compared to the reference concrete (Fig. 7a). These results confirm previous findings about the fact that the presence of pozzolanic admixtures was found to lower the detrimental effect of acid attack on concrete $[20,21]$. The mixes with rubber waste and fly ash show a resistance to sulphuric acid attack lower than the reference mix (Fig. 7b). The mix with $5 \%$ rubber waste and a partial replacement of cement by $15 \%$ fly ash and $15 \%$ metakaolin has almost the same resistance to sulphuric acid attack of the reference mix (Figs. 7c and 8). All the mixes with 45\% fly ash and 15\% metakaolin show a much higher resistance to sulphuric acid attack than the reference mix independently of the rubber waste content. Since the reference mix has much lower capillary water absorption than the mixes with $45 \%$ fly ash and $15 \%$ metakaolin this means that the rate of acid ingress into concrete has a lower influence than the solubility of calcium hydroxide that must be lower in the latter case. The mix complying with the requirements of EN 206-1 for concrete structures exposed to highly aggressive chemical environment (class XA3) showed a worst resistance to 

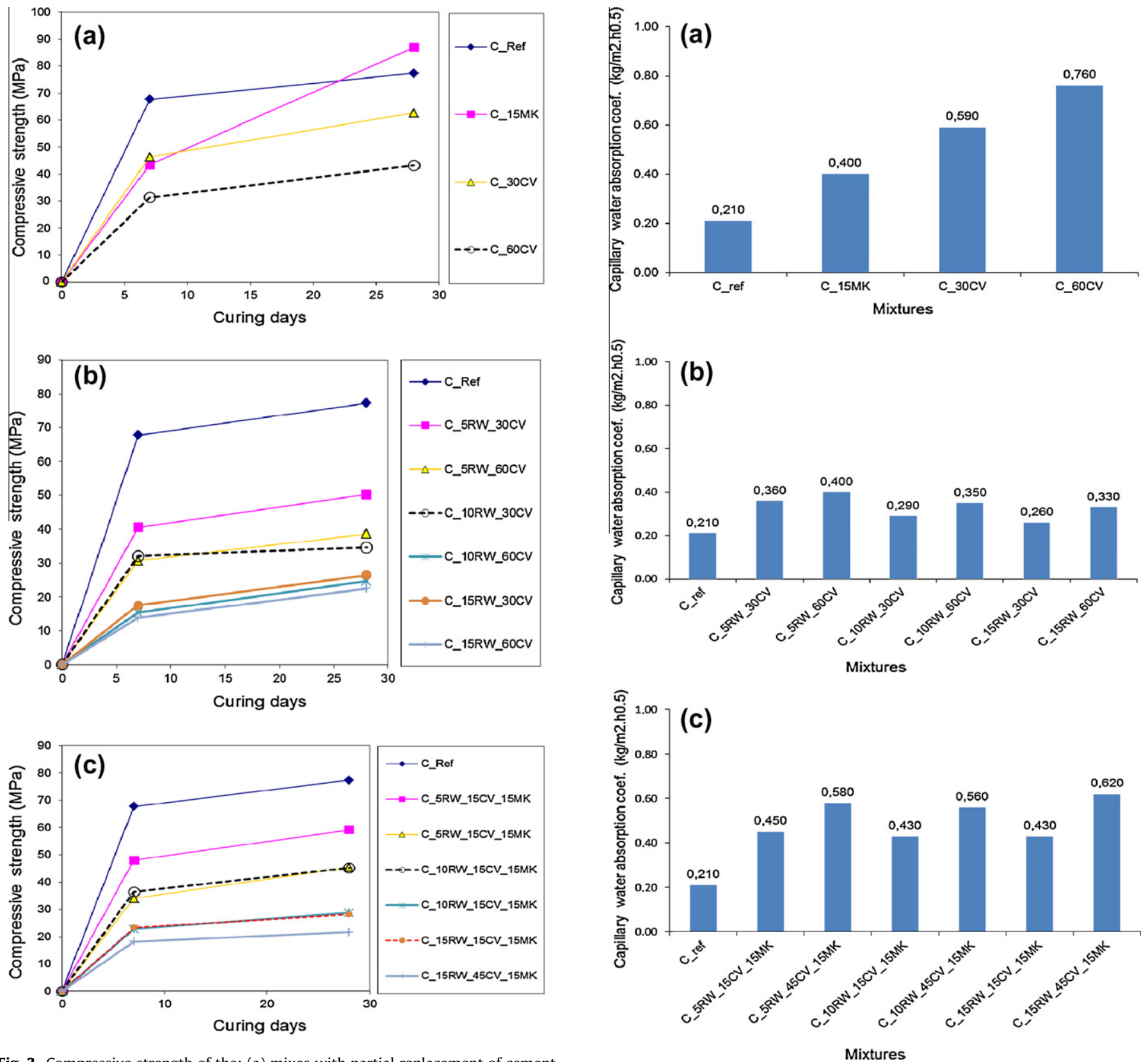

Fig. 3. Compressive strength of the: (a) mixes with partial replacement of cement by fly ash and metakaolin; (b) mixes with rubber wastes and partial replacement of cement by fly ash; (c) mixes with rubber wastes and partial replacement of cement by fly ash and by metakaolin.

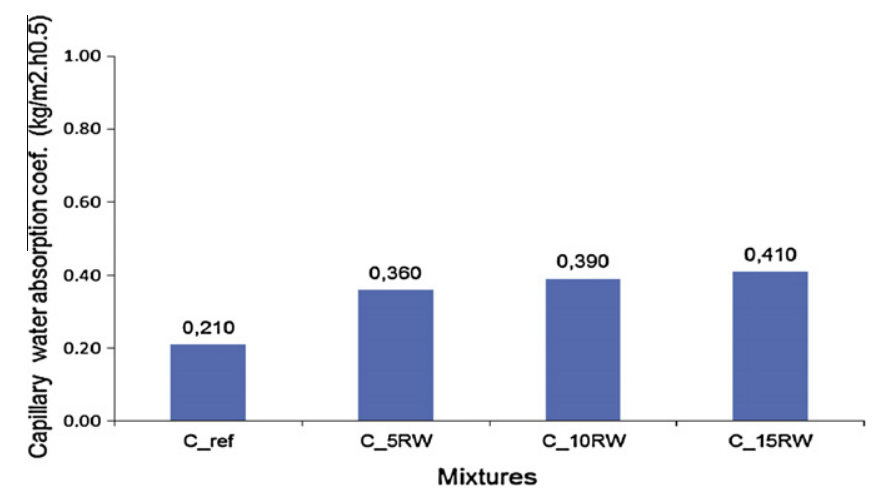

Fig. 4. Capillary water absorption coefficient of mixes with rubber wastes.

Fig. 5. Capillary water absorption coefficient of mixtures with: (a) partial replacement of cement by fly ash and by metakaolin; (b) rubber wastes and partial replacement of cement by fly ash; (c) rubber wastes and partial replacement of cement by fly ash and by metakaolin.

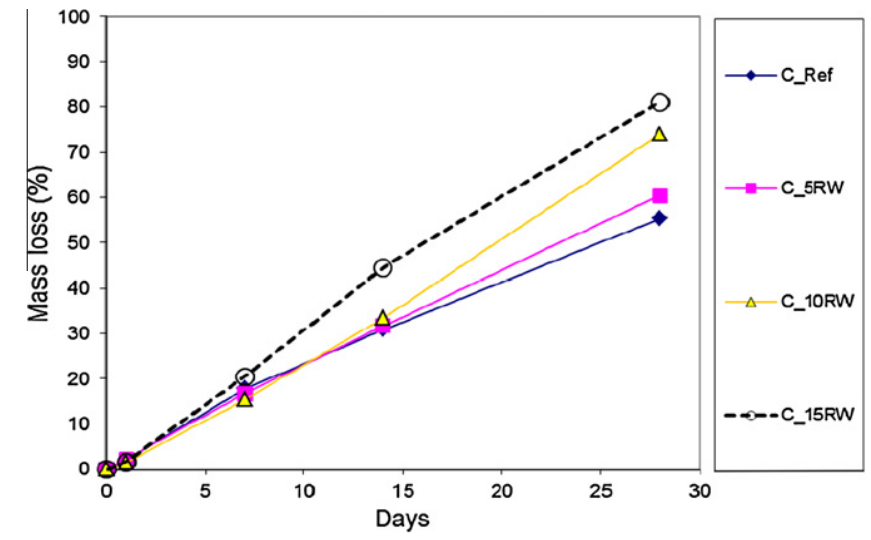

Fig. 6. Mass loss after sulphuric acid attack of mixes with rubber wastes. 

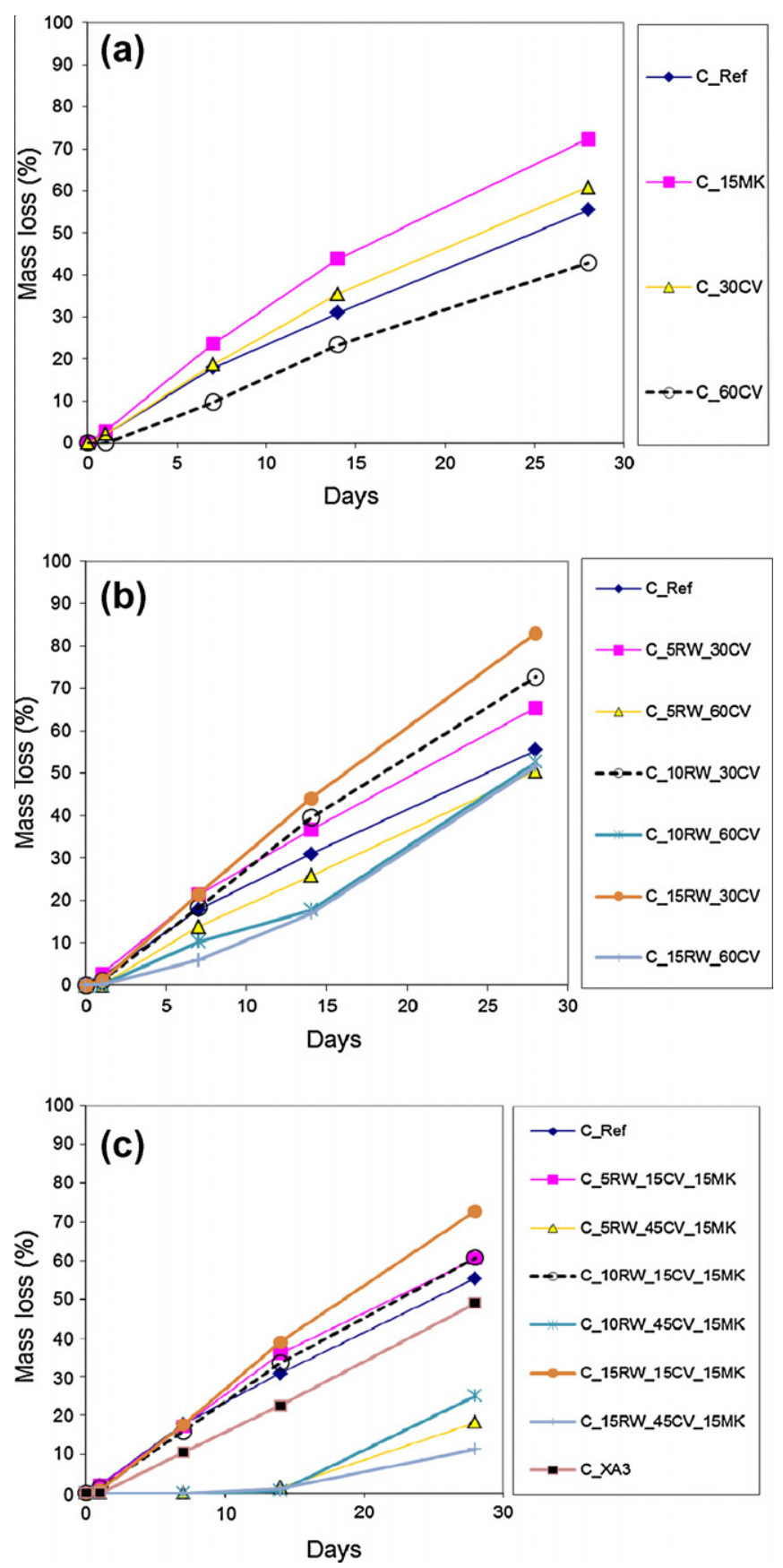

Fig. 7. Mass loss after sulphuric acid attack of mixes with: (a) partial replacement of cement by fly ash and by metakaolin; (b) rubber wastes and partial replacement of cement by fly ash; (c) rubber wastes and partial replacement of cement by fly ash and by metakaolin. sulphuric acid attack than the mixes containing rubber wastes and with $45 \%$ fly ash and $15 \%$ metakaolin. This means that the new mixes with rubber wastes, fly ash and metakaolin could be recommended for sulphuric acid resistance applications such as sewer pipes concrete, an hot area due to the rapid deterioration of concrete in sewage systems [22]. This also means that the requirements of EN 206-1 for concrete structures exposed to highly aggressive chemical environment should be revised.

\section{Conclusions}

From the information presented in this paper, the following conclusions can be drawn:

1. The increase of rubber wastes leads to serious compressive strength loss.

2. The synergetic effect between fly ash and metakaolin minimizes the strength loss associated to the use of rubber waste.

3. Is possible to use of rubber waste up to $15 \%$ and still maintain a low capillary water absorption.

4. The mix with $5 \%$ rubber waste and a partial replacement of cement by $15 \%$ fly ash and $15 \%$ metakaolin has almost the same resistance to sulphuric acid attack of the reference mix.

5. The mixes with $45 \%$ fly ash and $15 \%$ metakaolin show a much higher resistance to sulphuric acid attack than the reference mix independently of the rubber waste content.

6. The mix complying with the requirements of EN 206-1 for concrete structures exposed to highly aggressive chemical environment (class XA3) showed a worst resistance to sulphuric acid attack than the mixes containing rubber wastes, $45 \%$ fly ash and $15 \%$ metakaolin.

\section{References}

[1] Pacheco-Torgal F, Ding Y, Jalali S. Properties and durability of concrete containing polymeric wastes (tyre rubber and polyethylene terephthalate bottles): an overview. Constr Build Mater 2012;30:488-94.

[2] European Commission. Council directive 1999/31/EC of 26 April 1999 on the landfill of waste. Off J Eur Commun L182; 1999. p. 1-19.

[3] European Commission. Directive 2000/76/EC of the European Parliament and of the council of 4 December 2000 on incineration of waste. Off J Eur Commun L332; 2000. p. 91-111.

[4] Guneyisi E, Gesoglu M, Ozturan T. Properties of rubberized concretes containing silica fume. J Cem Concr Res 2004;34:2309-17.

[5] Aiello M, Leuzzi F. Waste tyre rubberized concrete: properties at fresh and hardened state. Waste Manage 2010;30:1696-704.

[6] Segre N, Monteiro P, Sposito G. Surface characterization of recycled tire rubber to be used in cement paste matrix. J Colloid Interf Sci 2002;248:521-3.

[7] Oikonomou N, Stefanidou M, Mavridou S. Improvement of the bonding between rubber tire particles and cement paste in cement products. In: 15 th Conference of the technical chamber of Greece, Alexandroupoli, Greece; 2006. p. 234-242.

[8] Chou L, Lin C, Lu C, Lee C, Lee M. Improving rubber concrete by waste organic sulfur compounds. Waste Manage Res 2010;28:29-35.

[9] Zheng L, Huo S, Yuan Y. Experimental investigation on dynamic properties of rubberized concrete. Constr Build Mater 2008;22:939-47.
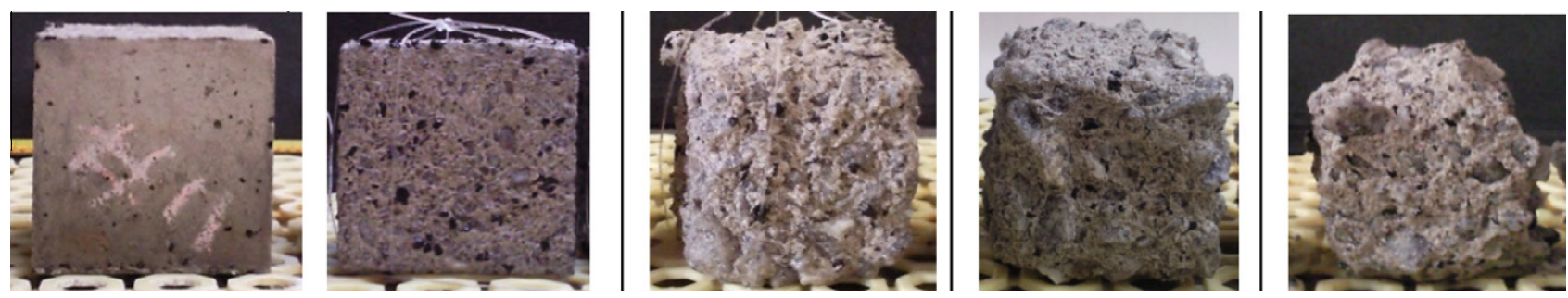

Fig. 8. Photos of concrete specimens with $5 \%$ rubber wastes and partial replacement of cement by $15 \%$ fly ash and by $15 \%$ metakaolin after immersion in sulphuric acid solution during $1,3,7,14$ and 28 days. 
[10] Neville A, Aïtcin P. High performance concrete - an overview. Mater Struct 1998;31:111-7.

[11] Faury J. Le Beton. Influence de ses constituents inerts. Regles á adopter pour sa meilheure composition. Sa confection et son transport sur les chantier. 3rd ed. Paris, France: Dunod; 1958.

[12] Lourenço J, Coutinho J. Automatic calculations for concrete mix selection. Faury and Bolomey methods. Coimbra, Portugal: Technical Documents; 1986.

[13] NP EN 206-1: 2007, Concrete. Part 1. Specification, performance, production and conformity.

[14] LNEC Portuguese Standard E393. Concrete: determination of capillarity water absorption, Lisboa; 1993.

[15] Boukni A, Swamy R, Bali A. Durability properties of containing 50\% and 65\% slag. Constr Build Mater 2009;23:2836-45.

[16] Lagier F, Kurtis K. Influence of Portland cement composition on early age reactions with metakaolin. Cem Concr Res 2007;37:1411-7.
[17] ERMCO - European ready-mixed concrete industry statistics - 2010; 2011.

[18] Pacheco-Torgal F, Gomes J. Influence of physical and geometrical properties of granite and limestone aggregates on the durability of a C20/25 strength class concrete. Constr Build Mater 2006;20:1079-88.

[19] Medeiros MHF, Helene P. Surface treatment of reinforced concrete in marine environment: influence on chloride diffusion coefficient and capillary water absorption. Constr Build Mater 2009;23:1476-84.

[20] Beddoe RE, Schmidt K. Acid attack on concrete - effect of concrete composition. Part 1. Cem Int 2009;7:88-94.

[21] Goyal S, Kumar M, Sidhu DS, Bhattacharjee B. Resistance of mineral admixture concrete to acid attack. J Adv Concr Technol 2009;7:273-83.

[22] Gutiérrez-Padilla M, Bielefeldt A, Ovtchinnikov S, Hernandez M, Silverstein J. Biogenic sulfuric acid attack on different types of commercially produced concrete sewer pipes. Cem Concr Res 2010;40:293-301. 